Marquette University

e-Publications@Marquette

School of Dentistry Faculty Research and

Publications

Dentistry, School of

$9-2015$

\title{
Fracture Resistance of Compromised Endodontically Treated Teeth Restored with Bonded Post and Cores: An in Vitro Study
}

Georgios Maroulakos

Marquette University, georgios.maroulakos@marquette.edu

William W. Nagy

Texas A\&M Health Science Center

Elias D. Kontogiorgos

Texas A\&M University

Follow this and additional works at: https://epublications.marquette.edu/dentistry_fac

Part of the Dentistry Commons

\section{Recommended Citation}

Maroulakos, Georgios; Nagy, William W.; and Kontogiorgos, Elias D., "Fracture Resistance of Compromised Endodontically Treated Teeth Restored with Bonded Post and Cores: An in Vitro Study" (2015). School of Dentistry Faculty Research and Publications. 156.

https://epublications.marquette.edu/dentistry_fac/156 


\title{
Fracture Resistance of Compromised Endodontically Treated Teeth Restored with Bonded Post and Cores: An in Vitro Study
}

\author{
Georgios Maroulakos \\ School of Dentistry, Department of General Dental Sciences, \\ Marquette University, \\ Milwaukee, WI \\ William W. Nagy \\ Baylor College of Dentistry, Department of Restorative Sciences, \\ Texas A\&M University, \\ Dallas, $T X$

\section{Elias D. Kontogiorgos} \\ Baylor College of Dentistry, Department of Restorative Sciences, \\ Texas A\&M University, \\ Dallas, $T X$
}

\begin{abstract}
Statement of problem: It is unclear which post and core system performs best when bonded to severely compromised endodontically treated teeth.

Purpose: The purpose of this study was to investigate the fracture resistance and mode of failure of severely compromised teeth restored with 3 different adhesively bonded post and core systems.
\end{abstract}


Material and methods: Thirty extracted endodontically treated maxillary anterior teeth were randomly divided into 3 groups, CPC, gold cast post and core; TPC, titanium prefabricated post/composite resin core; and FPC, quartz fiber reinforced post/composite resin core. All posts were adhesively cemented. All cores resembled a central incisor preparation with no remaining tooth structure above the finish line. Cast gold crowns were fabricated and cemented adhesively. The specimens were aged with thermocycling and cyclic loading. Two specimens per group were randomly selected for microcomputed tomographic imaging before and after aging. Failure was induced with a universal testing machine. The mode of failure was characterized by the interface separation. Data were analyzed with 1-way ANOVA $(a=.05)$ followed by post hoc tests (Bonferroni).

Results: A statistically significant difference was found among the 3 groups $(P=.002)$. CPC was significantly different than TPC $(P=.008)$ or FPC $(P=.003)$. The primary mode of failure for CPC and TPC was root fracture, and for FPC post debonding.

Conclusions: Severely compromised endodontically treated teeth restored with bonded gold cast post and cores showed significantly higher fracture resistance.

\section{Clinical Implications}

The use of bonded gold cast post and cores could increase the fracture resistance of structurally compromised endodontically treated teeth.

Caries and trauma result in the loss of coronal tooth structure. If the loss is substantial, the natural tooth structure cannot support a restoration, and a post is necessary to retain an artificial core that will restore the lost tooth structure. Remaining tooth structure is the most important factor for the long-term success of an endodontically treated tooth, irrespective of post type ${ }^{1}$ or post length. ${ }^{2}$ However, the real challenge is restoring endodontically treated teeth with inadequate remaining tooth structure. ${ }^{3}$ Procedures to address the lack of remaining structure include orthodontic extrusion and surgical crown lengthening. However, they may compromise the crown/root ratio, resulting in reduced static load failure of the teeth ${ }^{4}$ or unfavorable esthetic outcomes.

A ferrule is "a metal band or ring used to fit the root or crown of a tooth. ${ }^{\prime 5}$ It enhances the integrity of the endodontically treated tooth by counteracting functional lever forces, the wedging effect of tapered posts, and lateral forces during post insertion. ${ }^{6} \mathrm{~A}$ minimum of 1 to $2 \mathrm{~mm}$ of remaining tooth structure coronal to the finishing line is

The Journal of Prosthetic Dentistry, Vol 114, No. 3 (September 2015): pg. 390-397. DOI. This article is C) Elsevier and permission has been granted for this version to appear in e-Publications@Marquette. Elsevier does not grant permission for this article to be further copied/distributed or hosted elsewhere without the express permission from Elsevier. 
necessary to create an adequate ferrule. ${ }^{6,7}$ and 8 The role of the post is limited when more than $2 \mathrm{~mm}$ of tooth structure remain. ${ }^{9}$ and 10 Other critical factors may be the circumferential presence of tooth structure, ${ }^{11}$ its location, ${ }^{12}$ the ferrule width, remaining wall parallelism, the resin cement, and the post and core system used. ${ }^{13}$

Many different post and core systems are currently available and differ depending on the post type, design, surface texture, fit, and material. Studies that compare various post types have yielded controversial results favoring cast, 14,15 and 16 fiber reinforced, $17,18,19$, 20 and 21 titanium, ${ }^{20}$ stainless steel posts, ${ }^{22}$ or no specific type. ${ }^{22}$ and 23 Some did not standardize the cement used, and so the systems could not be directly compared. ${ }^{16}$ and 21 Resin cements exhibit a higher number of cycles to preliminary failure ${ }^{24}$ and better retention, ${ }^{25}$ and they appear to be the most suitable for the cementation of fiber posts. ${ }^{25}, 26,27,28,29,30,31,32,33$ and 34 They are also used to cement metal posts and can be used with metal primers that enhance the bond to composite resins. ${ }^{35}$ Resin cements find application in the monoblock theory, in which dentin, post, and core function as a cohesive unit. ${ }^{14}$ and 36

The oral cavity is not a static environment. Restorative materials are subjected to dynamic temperature and loading conditions. Simulating those conditions in vitro is essential. ${ }^{37,38,39}$ and 40 Endodontically treated teeth that cannot provide an adequate ferrule are the most challenging, and the selection of the right type of post may be an important success factor. No studies have compared bonded custom cast post and cores, titanium prefabricated posts/composite resin core, and quartz fiber posts/composite resin core in structurally compromised teeth in a simulated oral environment. The results may help to solve the dilemma of post selection in those situations.

The purpose of this in vitro study were to compare the fracture resistance of compromised endodontically treated teeth restored with 3 post and core systems and to characterize the types of failure in different groups. The null hypothesis was that no significant differences would be found among the 3 groups.

The Journal of Prosthetic Dentistry, Vol 114, No. 3 (September 2015): pg. 390-397. DOI. This article is (C) Elsevier and permission has been granted for this version to appear in e-Publications@Marquette. Elsevier does not grant permission for this article to be further copied/distributed or hosted elsewhere without the express permission from Elsevier. 
NOT THE PUBLISHED VERSION; this is the author's final, peer-reviewed manuscript. The published version may be accessed by following the link in the citation at the bottom of the page.

\section{Material and Methods}

Thirty freshly extracted human anterior maxillary teeth (central incisors, lateral incisors, canines) were obtained from patients of Texas A\&M University, Baylor College of Dentistry. Written consent was obtained in accordance with the institutional review board. The teeth were cleaned, disinfected (ProSpray C-60; Certol Intl), inspected under light magnification (Stemi DV4 8.0x; Carl Zeiss MicroImaging, Inc), and radiographed to ensure they were free of cracks or internal resorption. All teeth were sectioned leaving $15 \mathrm{~mm}$ of sound tooth structure above the root apex and endodontically treated by using the crown down technique ${ }^{41}$ with rotary NiTi instrumentation (EndoSequence; Brasseler) until apical instrumentation of ISO 40 and $5.25 \%$ sodium hypochlorite irrigation. The taper was $4 \%$ after chemomechanical preparation of the root canals. The canals were obturated with gutta percha cones (Dentsply Intl) with warm vertical compaction (sealer, AH Plus; Dentsply Intl). The cones were heat seared (System B; SymbronEndo) and compacted, leaving $4 \mathrm{~mm}$ of apical gutta percha seal and an $11 \mathrm{~mm}$ post space.

The teeth were mounted in acrylic resin with $12 \mathrm{~mm}$ of the tooth measured from the root tip embedded in the resin and the coronal 3 $\mathrm{mm}$ exposed above the resin block. All specimens were labeled and randomly assigned to 3 groups of 10 (Random Allocation Software 2.0). Each group represented a different restorative option: CPC (ParaPost XP-Lab), TPC (ParaPost XH), FPC (D.T. Light-Post) (Fig. 1). The mesiodistal (MD) and faciolingual (FL) dimensions of the teeth were measured coronally with a digital caliper (700-126; Mitutoyo). The mean MD, FL, and MD $\times$ FL of each group were calculated. The variances among the groups were homogenous (Levene test: $\left.\mathrm{p}_{\mathrm{MD}}=.374, \mathrm{p}_{\mathrm{FL}}=.208, \mathrm{p}_{\mathrm{MD} \times \mathrm{FL}}=.128\right)$. One-way ANOVA showed that the groups did not differ significantly regarding their dimensions $\left(F_{M D}[2,27]=1.020 / p=.374, F_{F L}[2,27]=1.663 / p=.208\right.$, $\left.\mathrm{F}_{\mathrm{MD} \times \mathrm{FL}}[2,27]=2.224 / \mathrm{p}=.128\right)$ and were considered dimensionally not different.

The Journal of Prosthetic Dentistry, Vol 114, No. 3 (September 2015): pg. 390-397. DOI. This article is (C) Elsevier and permission has been granted for this version to appear in e-Publications@Marquette. Elsevier does not grant permission for this article to be further copied/distributed or hosted elsewhere without the express permission from Elsevier. 


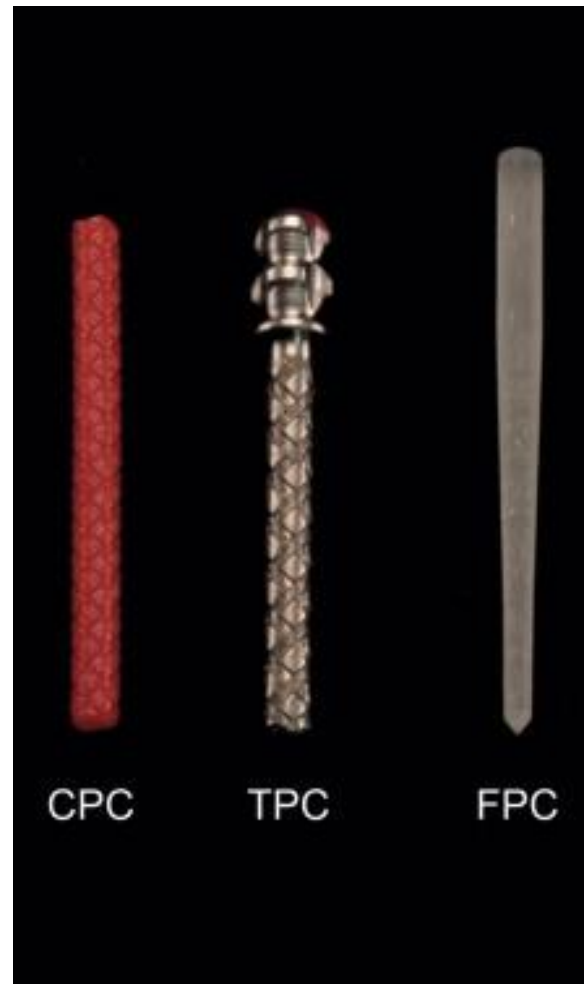

Figure 1. Photograph of 3 different post systems tested. CPC, Parapost XP-Lab (plastic pattern for custom cast post and core); TPC, Parapost XH (prefabricated titanium post); FPC, D.T. Light-Post (prefabricated quartz fiber post).

The preparation of the specimens for each group was as follows.

\section{Group CPC}

The post space was prepared to a size 5 (ParaPost; Coltène/Whaledent). A $4 \mathrm{~mm}$ long, $0.6 \mathrm{~mm}$ deep antirotation groove was made at the lingual aspect of the root canal with a tungsten carbide bur (no. 170; Brasseler). A circumferential 45-degree internal bevel was created at the axial angle of the root canal wall coronally with the same bur. The root canal was rinsed with chlorhexidine gluconate $0.12 \%$ (Peridex; 3M ESPE). A post and core pattern was made with a plastic pattern (ParaPost XP-Lab; Coltène/Whaledent) and chemically initiated acrylic resin (Pattern Resin LS; GC America). The pattern was invested (PowerCast; Whip Mix Corp) and cast in Type IV gold alloy (Ney-Oro 60; Dentsply Intl) with a centrifugal casting machine. The post was airborne-particle abraded (50 $\mu \mathrm{m}$ aluminum oxide particles, $400 \mathrm{kPa}$ for $2 \mathrm{~s} / \mathrm{cm}^{2}$ to a matte finish), water steamed, and air dried. Metal primer was applied according to manufacturer 
guidelines (Alloy Primer; Kuraray Noritake Dental Inc). The root canal was dried with paper cones. ED primer liquids A and B (Kuraray Noritake Dental Inc) were mixed at a 1:1 ratio for 4 seconds, applied into the canal with a thin brush, left for 60 seconds, and blown with a gentle stream of air to evaporate the volatiles. One full turn of Panavia 21 catalyst and of universal paste (Kuraray Noritake Dental Inc) were mixed for 20 seconds. A thick and even layer was applied on the post, which was seated with finger pressure for 60 seconds. Cement excess was removed with a brush. Glycerol gel (Oxyguard II; Kuraray Noritake Dental Inc) was applied for 3 minutes to prevent the formation of an oxygen-inhibited polymerization zone and then removed with air-water spray.

\section{Group TPC}

The procedure described for CPC regarding post/canal treatment and post cementation was followed. However, no antirotation groove was created. For the core, the dentin and post were etched with $34 \%$ phosphoric acid gel (Dentsply Intl) for 15 seconds. The etchant was rinsed with air-water spray for 10 seconds. Excess moisture was removed until there was no water pooling and the tooth surface was left slightly moist. Prime\&Bond NT adhesive (Dentsply Intl) was mixed with the autopolymerized activator for 2 seconds (ratio $1: 1$ ), applied on the tooth and post, and left for 20 seconds. Excess solvent was removed by air-drying for 10 seconds, beginning $10 \mathrm{~cm}$ away from the specimen and gradually closing to $1 \mathrm{~cm}$. The air-dried surface remained glossy and not desiccated. The adhesive was light polymerized for 10 seconds (Demi Plus; Kerr Corp). Equal quantities of the core paste and catalyst were mixed for 30 seconds (Fluorocore Blue; Dentsply Intl). The mix was placed in a clear form (Paracore; Coltène/Whaledent), seated on the tooth, light polymerized for 40 seconds, and left for an additional 7 minutes of autopolymerization. Finally, the form was removed and light polymerized for another 40 seconds.

\section{Group FPC}

The post space was prepared to a size 1 (DT-Light Post; Bisco Inc). The procedure described for CPC regarding root canal treatment

The Journal of Prosthetic Dentistry, Vol 114, No. 3 (September 2015): pg. 390-397. DOI. This article is (c) Elsevier and permission has been granted for this version to appear in e-Publications@ Marquette. Elsevier does not grant permission for this article to be further copied/distributed or hosted elsewhere without the express permission from Elsevier. 
and post cementation was followed. However, no antirotation groove was created, and the post surface was left untreated. The procedure described above for TPC regarding core fabrication was followed for FPC.

\section{Crown fabrication and cementation}

All cores were prepared $6 \mathrm{~mm}$ incisal to the finish line facially and $3 \mathrm{~mm}$ incisal to the finish line lingually, simulating a central incisor preparation with no remaining tooth structure above the finish line. The finish line was a $1-\mathrm{mm}$ wide circumferential shoulder $3 \mathrm{~mm}$ coronal to the resin block with a flat end, medium grit, tapered diamond (847/018; Brasseler). Crown wax patterns were made directly on the specimens with a polyvinyl siloxane putty index (Lab Putty; Coltène/Whaledent), simulating the anatomy of an $11 \mathrm{~mm}$ tall central incisor, and had a lingual notch $3 \mathrm{~mm}$ apical to the incisal edge. They were invested and cast in Type IV gold alloy (Ney-Oro 60; Dentsply IntI). All crowns were treated and cemented as for group CPC with Panavia 21. However, the ED primer was applied only on the margin for CPC, whereas for TPC and FPC it was applied on both the tooth margin and core following the manufacturer's guidelines. Cement excess was removed with a brush. Glycerol gel was then applied for 3 minutes and removed with air-water spray. The materials used are listed in Table 1. Figure 2 illustrates the dimensions of the post, core, and crown for each group.

Table 1. Materials used

\begin{tabular}{|c|c|c|c|c|}
\hline Product & Characteristic & Composition & Batch No. & Manufacturer \\
\hline $\begin{array}{l}\text { Parapost } \\
\text { XP-Lab } \\
\text { (CPC) }\end{array}$ & $\begin{array}{l}\text { Parallel sided, } \\
\text { size } 5,1.22 \mathrm{~mm} \\
\text { diameter }\end{array}$ & Plastic burn-out patterns & MT-118550 & Coltène/Whaledent \\
\hline $\begin{array}{l}\text { Parapost } \\
\text { XH (TPC) }\end{array}$ & $\begin{array}{l}\text { Parallel sided, } \\
\text { size } 5,1.22 \mathrm{~mm} \\
\text { diameter }\end{array}$ & Titanium alloy & MT-118585 & Coltène/Whaledent \\
\hline $\begin{array}{l}\text { D.T. Light- } \\
\text { Post (FPC) }\end{array}$ & $\begin{array}{l}\text { Tapered, size } 1 \text {, } \\
1.50 \mathrm{~mm} \\
\text { diameter }\end{array}$ & $\begin{array}{l}\text { Quartz fibers bound in epoxy } \\
\text { matrix }\end{array}$ & 1100000597 & Bisco Inc \\
\hline $\begin{array}{l}\text { Pattern } \\
\text { Resin LS }\end{array}$ & & $\begin{array}{l}\text { Powder: } \\
\text { polymethylmethacrylate, } \\
\text { polymethylmethacrylate, } \\
\text { dibenzoyl peroxide } \\
\text { Liquid: methylmethacrylate, 2- } \\
\text { hydroxyethyl-methacrylate }\end{array}$ & 0911206 & GC America \\
\hline Panavia 21 & & $\begin{array}{l}\text { Paste: } 10 \text {-methacryloyloxydecyl } \\
\text { dihydrogen phosphate, }\end{array}$ & 61218 & $\begin{array}{l}\text { Kuraray Noritake } \\
\text { Dental Inc }\end{array}$ \\
\hline
\end{tabular}

The Journal of Prosthetic Dentistry, Vol 114, No. 3 (September 2015): pg. 390-397. DOI. This article is (C) Elsevier and permission has been granted for this version to appear in e-Publications@Marquette. Elsevier does not grant permission for this article to be further copied/distributed or hosted elsewhere without the express permission from Elsevier. 
NOT THE PUBLISHED VERSION; this is the author's final, peer-reviewed manuscript. The published version may be accessed by following the link in the citation at the bottom of the page.

\section{Product Characteristic}

\section{Composition}

hydrophobic aromatic dimethacrylate, hydrophobic aliphatic dimethacrylate, silanated silica filler ED primer: 2-hydroxyethyl methacrylate, 10 methacryloyloxydecy dihydrogen phosphate, $\mathrm{N}$ methacryloyl-5-aminosalicylic acid

Oxyguard II: glycerol, polyethylene glycol

\section{Alloy}

Primer

Prime \&

Bond NT

Dual Cure

Fluorocore

Blue

Ney-Oro

60
6-(4-Vinylbenzyl-N-

propyl)amino-1,3,5-triazine-2,4 dithione, 10-MDP

Prime and bond NT: urethane dimethacrylate resin, dipentaerythritol pentaacrylate phosphate, polymerizable dimethacrylate/ trimethacrylate resins, acetone Self-cure activator: acetone, urethane dimethacrylate monomer, 2-hydroxyethyl methacrylate, diphenyl $(2,4,6$ trimethylbenzoyl)phosphine Caulk 34\% tooth conditioner gel: Phosphoric acid

Barium fluoroaluminoborosilicate 100902

glass, treated hydrophobic

fumed silica, urethane

dimethacrylate resin, urethane

modified bis-GMA

dimethacrylate resin, polymerizable

dimethacrylate/trimethacrylate resin

Au 56.0, Pd 4.0, Ag 19.9, Cu 17.0, Zn/Ir trace
Batch No. Manufacturer
Kuraray Noritake Dental Inc

Dentsply Intl
Dentsply Intl

Dentsply Intl

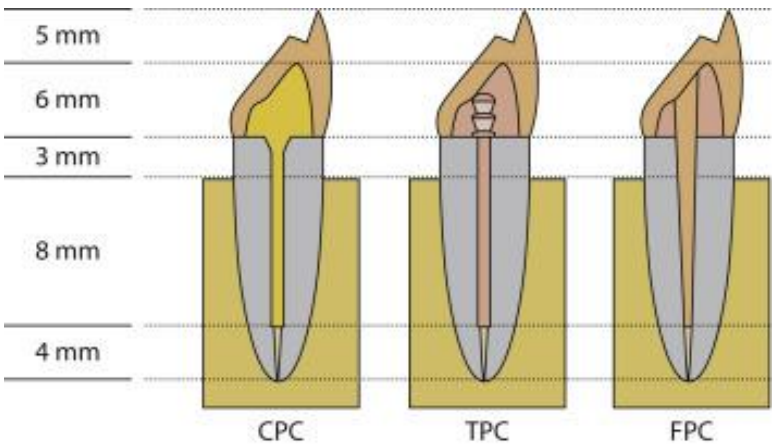

Figure 2. Schematic dimensions of post, core, and crown for each group. CPC, custom gold cast post and core; TPC, prefabricated titanium post/composite resin core; FPC, prefabricated quartz fiber reinforced post/composite resin core.

The Journal of Prosthetic Dentistry, Vol 114, No. 3 (September 2015): pg. 390-397. DOI. This article is (C) Elsevier and permission has been granted for this version to appear in e-Publications@Marquette. Elsevier does not grant permission for this article to be further copied/distributed or hosted elsewhere without the express permission from Elsevier. 


\section{Aging and testing procedures}

All specimens were stored in saline for 1 week before testing. Two specimens per group were randomly selected to obtain microcomputed tomographic $(\mu \mathrm{CT})$ imaging in order to detect microcracks that could have occurred as a result of root canal treatment, post space preparation, or post cementation. The 6 specimens were scanned ( $\mu$-CT35; Scanco Medical AG) at $10 \mu \mathrm{m}$ voxel size isotropic resolution ( $E=70 \mathrm{kVp}, \mathrm{I}=114 \mu \mathrm{A}, 1000$ projections over a total rotation of 180 degrees, integration time $800 \mathrm{~ms}$ ). Each scan was programmed to include the root of the specimens, resulting in 1500 slices $(15 \mathrm{~mm})$ and 3.5 hours of scanning time. All specimens were thermocycled by immersion in 2 water tanks (cold, warm) with temperatures of $5^{\circ} \mathrm{C}$ and $55^{\circ} \mathrm{C}$ ( 16 seconds cold, 16 seconds warm, 4 seconds transfer) for a total of 6000 cycles, which represents approximately 7 months of clinical service. ${ }^{37}$ A universal testing machine (MTS 858 Mini Bionix II; MTS Systems) was used to cyclically load the specimens at a 135degree angle to their long axis ${ }^{12}$ with a 0 to $50 \mathrm{~N}$ load applied at the lingual notch at a frequency of $2 \mathrm{~Hz}$ for a total of 50000 cycles, which reflects approximately 3 to 12 months of clinical service (Fig. 3). ${ }^{38}$ The 6 specimens that were evaluated with $\mu \mathrm{CT}$ before fatigue were rescanned to evaluate failure tendencies. Finally, clinical failure was induced with a universal testing machine (model 5567; Instron) with a load cell of maximum capacity of $1000 \mathrm{~N}$. The compressive force was applied at 135 degrees to the long axis at the lingual notch with a crosshead speed of $0.5 \mathrm{~cm} / \mathrm{min} .{ }^{12}$ The force applied to the specimen over time was recorded. Failure was defined as the load recorded when the force-time graph showed a sudden drop, indicating a sudden decrease of the specimen's resistance to compressive stress.

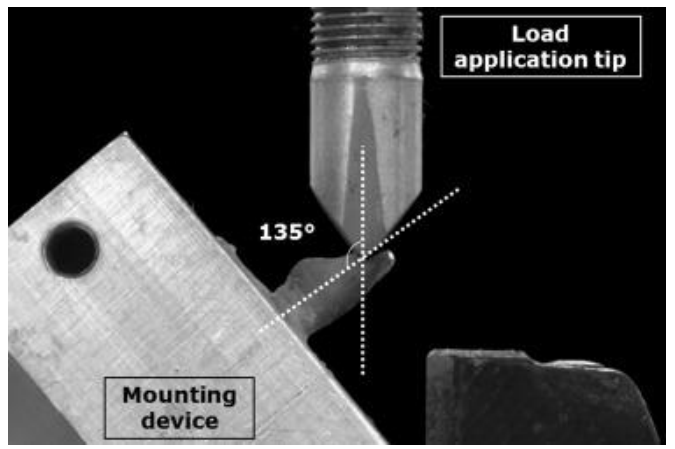

Figure 3. Specimen configuration for load test on universal testing machine.

The Journal of Prosthetic Dentistry, Vol 114, No. 3 (September 2015): pg. 390-397. DOI. This article is @ Elsevier and permission has been granted for this version to appear in e-Publications@Marquette. Elsevier does not grant permission for this article to be further copied/distributed or hosted elsewhere without the express permission from Elsevier. 
Sample size was calculated with $80 \%$ power to detect differences among groups at $a=.05$ using statistical software (G*Power 3.1.9.2; Erdfelder, Faul \& Buchner). The mean failure values for each group were calculated in newtons. The normality of distribution in each group was tested with the Shapiro-Wilk test. The homogeneity of variances among the groups was tested with the Levene test. One-way ANOVA was used to identify differences within and between the groups using "load" as a dependent variable $(a=.05)$, and post hoc tests (Bonferroni correction) were used to locate differences (SPSS v19.0; IBM Corp). In addition, the specimens were observed under the light microscope to characterize failures. The failures were classified as follows: failure of the crown (crown fracture, Type 1), the crown-core interface (crown debonding, Type 2), the post (post fracture, Type 3), the post-dentin interface (post debonding Type, 4), or the dentin (root fracture, Type 5).

\section{Results}

The mean (SD) failure value of CPC was $174.0 \mathrm{~N}(51.0)$, of TPC $123.5 \mathrm{~N}$ (23.4), and of FPC $117.6 \mathrm{~N}$ (19.3) (Table 2). One-way ANOVA showed statistically significant differences among the groups $[F(2,27)=8.197, P=.002]$. The fracture resistance of CPC was higher than either TPC $(P=.008)$ or FPC $(P=.003)$. The fracture resistance of TPC was not significantly different than FPC $(P=1.000)$ ( Table 3$)$.

Table 2. Descriptive statistics for each group

Fracture Resistance (N)

Mean

Standard deviation

Minimum

Maximum

Shapiro-Wilka

Levene ${ }^{b}$

Group size

bHomogeneity of variances among groups was verified with Levene test $(P>05)$

The Journal of Prosthetic Dentistry, Vol 114, No. 3 (September 2015): pg. 390-397. DOI. This article is (c) Elsevier and permission has been granted for this version to appear in e-Publications@Marquette. Elsevier does not grant permission for this article to be further copied/distributed or hosted elsewhere without the express permission from Elsevier. 
NOT THE PUBLISHED VERSION; this is the author's final, peer-reviewed manuscript. The published version may be accessed by following the link in the citation at the bottom of the page.

Table 3. Inferential statistical results

\begin{tabular}{lllllc}
\multicolumn{1}{c}{ ANOVA } & \multicolumn{1}{c}{ Sum of Squares } & \multicolumn{1}{c}{$\boldsymbol{d f}$} & Mean Square & \multicolumn{1}{c}{$\mathbf{F}$} & $\boldsymbol{P}$ \\
Between groups & 19239.022 & 2 & 9619.511 & 8.197 & .002 \\
Within groups & 3684.793 & 27 & 1173.511 & & \\
Total & 50923.815 & 29 & & & \\
Post hoc Bonferroni & Group & & & Mean \\
& CPC & & & $174.0^{\mathrm{a}, \mathrm{b}}$ \\
& TPC & & & $123.5^{\mathrm{b}}$ \\
& FPC & & & $117.6^{\mathrm{a}}$
\end{tabular}

a,b Differences between mean values with same superscript were significantly different $(P \leq .05)$.

Evaluation of the $\mu \mathrm{CT}$ images taken before and after aging of the 6 selected teeth led to the following observations. The best-quality images were obtained with the specimens restored with fiber or titanium prefabricated post/composite resin core. The specimens restored with a custom cast post and core showed a great amount of scatter that made evaluation difficult. The before-aging scans showed an absence of microcracks in the radicular dentin. However, voids between the post and the radicular dentin were evident in many slices along the root of the evaluated specimens. Microgaps were evident within the body of the fiber posts. The after-aging scans were not remarkably different from the before-aging scans (Fig. 4).

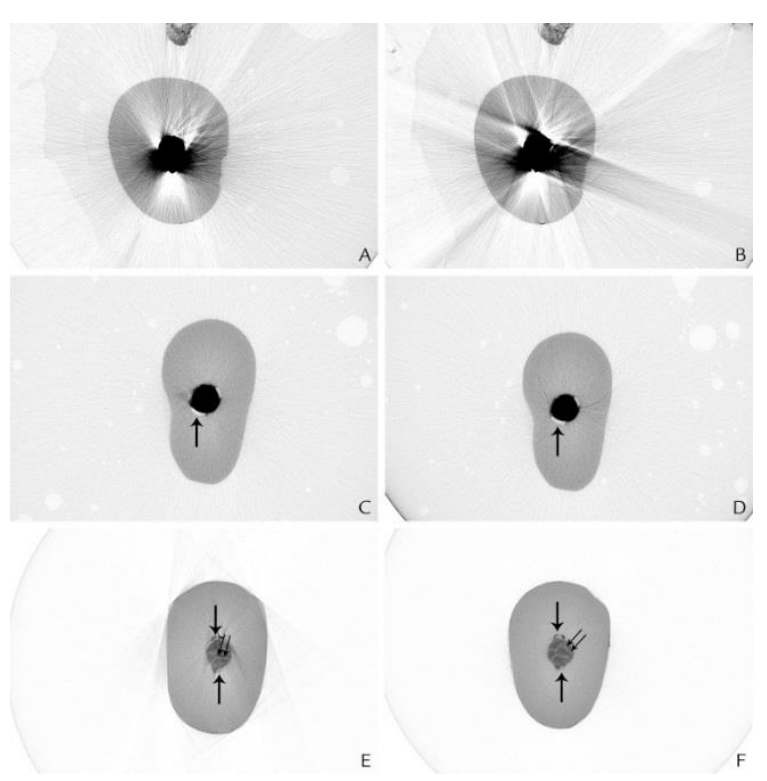

Figure 4. Inverted $\mu C T$ images of representative specimens. $A$, Custom gold cast post before aging. B, Custom gold cast post after aging. C, Titanium prefabricated post before aging. D, Titanium prefabricated post after aging. E, Quartz fiber reinforced 
post before aging. F, Quartz fiber reinforced post after aging. Single black arrows ( $\uparrow)$, cement voids; double black arrows $(\uparrow \uparrow)$, microgaps in fiber posts.

The primary mode of failure for CPC was root fracture (Type 5). In 2 specimens, the post was debonded, and in 1 the post was fractured (Type 3). For TPC, all specimens but 1 failed by root fracture (Type 5), while in 1 the post was debonded. Finally, for FPC, the primary mode of failure was post debonding (Type 4), while 3 of the specimens failed by root fracture (Fig. 5). In all cases of root fracture, the fracture line was located on the mesial or distal aspect of the root. In the cases of post debonding, for CPC and TPC, remnants of the cement could be seen on the post surface, while for FPC no cement was noticed on the post surface after post debonding. None of the groups exhibited failure of the core/crown interface.

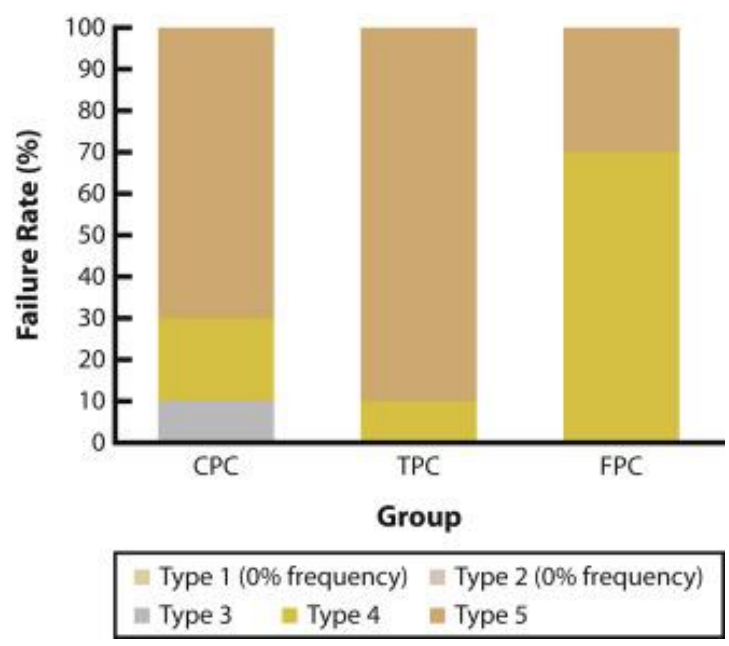

Figure 5. Frequency rate of failure modes observed for each group. Type 1, crown fracture; Type 2, crown debonding; Type 3, post fracture; Type 4, post debonding; Type 5, root fracture; CPC, custom gold cast post and core; TPC, prefabricated titanium post/composite resin core; FPC, prefabricated quartz fiber reinforced post/composite resin core.

\section{Discussion}

This study showed that group CPC performed better than TPC and FPC. The results support the rejection of the null hypothesis that the fracture resistance of the 3 groups would not be statistically different. In addition, modes of failure were different among the groups.

The Journal of Prosthetic Dentistry, Vol 114, No. 3 (September 2015): pg. 390-397. DOI. This article is (C) Elsevier and permission has been granted for this version to appear in e-Publications@Marquette. Elsevier does not grant permission for this article to be further copied/distributed or hosted elsewhere without the express permission from Elsevier. 
Previous studies that compared different posts show various and sometimes confusing results. An in vitro study ${ }^{17}$ comparing the fracture resistance of adhesively cemented titanium, prefabricated, glass fiber, and carbon fiber posts on teeth with $2 \mathrm{~mm}$ of remaining tooth structure favored titanium posts. However, the teeth were not restored with crowns, negating the ferrule effect. Another compared metallic with nonmetallic posts cemented with adhesive or nonadhesive cements on teeth with $2 \mathrm{~mm}$ of remaining tooth structure. ${ }^{18}$ The authors concluded that fiber posts showed greater fracture resistance than cast post and cores and that the use of resin cement did not improve the performance of metallic posts. Other studies using static loads favored cast and titanium prefabricated over fiber posts, ${ }^{14}$ cast over fiber ${ }^{16}$ cast and fiber over titanium and stainless steel, ${ }^{19}$ or prefabricated fiber and titanium over custom zirconia and cast posts. ${ }^{20}$ The fracture resistance rates varied from 300 to $600 \mathrm{~N}$ or higher, $17,18,19$ and 20 rates significantly higher than the ones observed in this study. This may be attributed to the various levels of remaining tooth structure used, whereas in our study there was no remaining tooth structure. However, in a study in which similar materials and failure protocol were used to compare titanium prefabricated and quartz fiber posts, the values of fracture resistance of the studied groups were as high as in the previous studies, approximately $500 \mathrm{~N} .{ }^{23}$ Similarly, in this current study, these groups showed similar fracture resistance but at much lower fracture values, possibly caused by the combination of cyclic loading and thermal fatigue that was not present in the previous study. Another study, in which the same post systems were used (ParaPost XP and Parapost $\mathrm{XH}$ ) in teeth with $1 \mathrm{~mm}$ of remaining tooth structure, showed more comparable results, 207.3 (13.5) $\mathrm{N}$ for the cast post and core group and 284.7 (16.4) $\mathrm{N}$ for the titanium prefabricated post group. ${ }^{14}$ However, the post surface was not treated, and no artificial aging was performed. A study comparing adhesively cemented zirconia, glass fiber, stainless steel, and cast posts did not show any statistical difference among the groups, but the zirconia posts showed the lowest number of load cycles to failure and metal posts the highest. ${ }^{22}$ The amount of remaining tooth structure was not reported, and whether crowns were fabricated was not specified. Other studies using dynamic loading favored fiber over metal prefabricated ${ }^{21}$ and cast over fiber posts. ${ }^{15}$

The Journal of Prosthetic Dentistry, Vol 114, No. 3 (September 2015): pg. 390-397. DOI. This article is @ Elsevier and permission has been granted for this version to appear in e-Publications@Marquette. Elsevier does not grant permission for this article to be further copied/distributed or hosted elsewhere without the express permission from Elsevier. 
In the present study, group CPC showed significantly higher fracture resistance compared with FPC. This may be attributed to better adaptation of the cast posts or better bond to resin cements, especially when they are treated with primers. ${ }^{35}$ Also, the double tapered design and absence of serrations in the fiber posts may have reduced their mechanical retention. Previous research suggests that altering the surface of fiber posts can improve the bond to resin. Several materials have been used; 28,29 and 30 however, there is no consensus that one material is better, and most manufacturers do not recommend altering the surface of fiber posts. Also, the effect of airborne-particle abrasion on fiber post morphologic characteristics and properties is not well defined and cannot be applied safely to all systems. ${ }^{31}$ The poorer bond quality was also verified by the main failure mode, post debonding, and the absence of adhered cement on the debonded fiber posts. This was in agreement with existing data supporting post debonding as the major failure pattern of fiber posts and less frequent root fracture. ${ }^{32}$ and 33 Group CPC showed greater fracture resistance compared with TPC. TPC exhibited the highest rate of root fracture at significantly lower force. The higher modulus of elasticity of titanium posts compared with posts made of gold alloys, fiber posts, and dentin ${ }^{36}$ may have resulted in higher stresses being transferred to dentin during loading.

To evaluate the clinical significance of these findings, the results should be compared with reported maximum occlusal forces on anterior teeth. In one study, the mean maximum anterior tooth occlusal force was 200 to $228 \mathrm{~N} .{ }^{39}$ Another study reported a mean maximum incisor occlusal force of 93 to $150 \mathrm{~N}$ for a white and 140 to $206 \mathrm{~N}$ for an indigenous Brazilian population. ${ }^{40}$ On the basis of these findings, 180 to $200 \mathrm{~N}$ of fracture resistance can be considered a safe evaluation threshold. Among the groups, only CPC, with a mean of 174 $\mathrm{N}$, approaches this threshold. This is in agreement with the clinical guideline for using custom cast post and cores in structurally compromised teeth. ${ }^{3}$

Using teeth with no remaining tooth structure allowed a direct comparison among the post systems without the influence of the ferrule effect. This allowed direct load transfer to the root, and despite being previously used for compromised teeth, ${ }^{23}$ it may be a limitation of the study. Also, a gentle air stream was used to evaporate the

The Journal of Prosthetic Dentistry, Vol 114, No. 3 (September 2015): pg. 390-397. DOI. This article is @ Elsevier and permission has been granted for this version to appear in e-Publications@Marquette. Elsevier does not grant permission for this article to be further copied/distributed or hosted elsewhere without the express permission from Elsevier. 
volatiles of the ED primer, as indicated by the manufacturer. However, other studies have shown an improved bond strength when paper points, ${ }^{42}$ paper points with air-drying, ${ }^{43}$ or intracanal air-drying are used to remove the solvent and excess adhesive. ${ }^{44}$ The resin cement was applied only on the post, which may have resulted in the observed cement voids. The use of a rotary spiral paste filler reduces that possibility, ${ }^{34}$ but it is contraindicated by the manufacturer. Another potential limitation was the fact that clinical failure was used to determine when the specimens failed. However, it is uncommon that posts fail after a single catastrophic force. Preliminary failure occurs as a result of micromovement of the crown margin in relation to the tooth. This occurs much earlier than clinically visible failure and is not as easily detected. ${ }^{7}$ This can be particularly important in the case of bonded posts, because when clinical failure occurs, it may lead to an eventually nonrestorable tooth. The low fracture resistance rates in our study could be partly explained by the aging-induced degradation of the adhesive interfaces (storage in water, thermocycling and cyclic loading fatigue). Finally, the results of this study may be directly related to the materials/methodology used and may not reflect what would happen under different conditions. The resin cement used was allowed to set at room temperature $\left(23^{\circ} \mathrm{C}\right)$, which is lower than body temperature. As shown with other adhesive cements, the degree of polymerization, polymerization shrinkage, and reaction kinetics and timing may have been affected by the experimental conditions. ${ }^{45}$ and 46 The failure loading protocol did not include a dynamic approach that could reproduce the oral conditions more closely. Future studies should compare groups with different levels of less than ideal tooth structure by using an accelerated fatigue protocol to explore the influence of the interaction between post type and remaining tooth structure on the fatigue resistance of endodontically treated teeth.

\section{Conclusions}

Within the limitations of this in vitro study, the following conclusions were drawn:

1. The type of post and core system significantly influences the fracture resistance of structurally compromised endodontically

The Journal of Prosthetic Dentistry, Vol 114, No. 3 (September 2015): pg. 390-397. DOI. This article is C) Elsevier and permission has been granted for this version to appear in e-Publications@Marquette. Elsevier does not grant permission for this article to be further copied/distributed or hosted elsewhere without the express permission from Elsevier. 
treated teeth. The bonded gold cast post and core showed higher fracture resistance than the other systems tested.

2. Teeth restored with quartz fiber posts exhibit more favorable failure patterns but at a very low fracture resistance value.

\section{Acknowledgments}

The authors thank Dr Jorge Jaramillo Otero, International Fellow at the Department of Endodontics, Texas A\&M University, Baylor College of Dentistry, for performing the endodontic treatment to the specimens; and Lilly Guo, Research Associate at the Department of Biomaterials, for her help executing the experiments with the Instron and MTS machines.

\section{References}

${ }^{1} \mathrm{~F}$. Isidor, K. Brondum, G. Ravnholt. The influence of post length and crown ferrule length on the resistance to cyclic loading of bovine teeth with prefabricated titanium posts. Int J Prosthodont, 12 (1999), pp. 78-82

${ }^{2}$ A.R. Giovani, L.P. Vansan, M.D. de Sousa Neto, S.M. Paulino. In vitro fracture resistance of glass-fiber and cast metal posts with different lengths. J Prosthet Dent, 101 (2009), pp. 183-188

${ }^{3} \mathrm{~A}$. Torbjorner, B. Fransson.A literature review on the prosthetic treatment of structurally compromised teeth. Int J Prosthodont, 17 (2004), pp. 369-376

${ }^{4}$ A.G. Gegauff.Effect of crown lengthening and ferrule placement on static load failure of cemented cast post-cores and crowns. J Prosthet Dent, 84 (2000), pp. 169-179

${ }^{5}$ The glossary of prosthodontic terms. J Prosthet Dent, 94 (2005), pp. 10-92

${ }^{6} \mathrm{~J}$.A. Sorensen, M.J. Engelman. Ferrule design and fracture resistance of endodontically treated teeth. J Prosthet Dent, 63 (1990), pp. 529-536

${ }^{7}$ W.J. Libman, J.I. Nicholls. Load fatigue of teeth restored with cast posts and cores and complete crowns. Int J Prosthodont, 8 (1995), pp. 155-161

${ }^{8}$ C.C. Ng, M.I. al-Bayat, H.B. Dumbrigue, J.A. Griggs, C.W. Wakefield. Effect of no ferrule on failure of teeth restored with bonded posts and cores. Gen Dent, 52 (2004), pp. 143-146

${ }^{9}$ P. Milot, R.S. Stein. Root fracture in endodontically treated teeth related to post selection and crown design. J Prosthet Dent, 68 (1992), pp. 428435

${ }^{10}$ D. Assif, E. Oren, B.L. Marshak, I. Aviv. Photoelastic analysis of stress transfer by endodontically treated teeth to the supporting structure using different restorative techniques. J Prosthet Dent, 61 (1989), pp. 535-543

The Journal of Prosthetic Dentistry, Vol 114, No. 3 (September 2015): pg. 390-397. DOI. This article is (C) Elsevier and permission has been granted for this version to appear in e-Publications@Marquette. Elsevier does not grant permission for this article to be further copied/distributed or hosted elsewhere without the express permission from Elsevier. 
NOT THE PUBLISHED VERSION; this is the author's final, peer-reviewed manuscript. The published version may be

accessed by following the link in the citation at the bottom of the page.

${ }^{11}$ P.L. Tan, S.A. Aquilino, D.G. Gratton, C.M. Stanford, S.C. Tan, W.T. Johnson, et al. In vitro fracture resistance of endodontically treated central incisors with varying ferrule heights and configurations. J Prosthet Dent, 93 (2005), pp. 331-336

${ }^{12}$ C.C. Ng, H.B. Dumbrigue, M.I. Al-Bayat, J.A. Griggs, C.W. Wakefield. Influence of remaining coronal tooth structure location on the fracture resistance of restored endodontically treated anterior teeth. $J$ Prosthet Dent, 95 (2006), pp. 290-296

${ }^{13}$ Y. Goto, E.J. Swift Jr. Ferrules for endodontically treated teeth. J Esthet Restor Dent, 21 (2009), pp. 292-293

${ }^{14}$ C.J. Cormier, D.R. Burns, P. Moon. In vitro comparison of the fracture resistance and failure mode of fiber, ceramic, and conventional post systems at various stages of restoration. J Prosthodont, 10 (2001), pp. 26-36

${ }^{15}$ A. Sahafi, A. Peutzfeldt, G. Ravnholt, E. Asmussen, K. Gotfredsen. Resistance to cyclic loading of teeth restored with posts. Clin Oral Investig, 9 (2005), pp. 84-90

${ }^{16} \mathrm{G}$. Varvara, G. Perinetti, D. Di Iorio, G. Murmura, S. Caputi. In vitro evaluation of fracture resistance and failure mode of internally restored endodontically treated maxillary incisors with differing heights of residual dentin. J Prosthet Dent, 98 (2007), pp. 365-372

${ }^{17}$ A.M. Al-Wahadni, S. Hamdan, M. Al-Omiri, M.M. Hammad, M.M. Hatamleh. Fracture resistance of teeth restored with different post systems: in vitro study. Oral Surg Oral Med Oral Pathol Oral Radiol Endod, 106 (2008), pp. e77-e83

${ }^{18}$ X.H. Gu, M. Kern. Fracture resistance of crowned incisors with different post systems and luting agents. J Oral Rehabil, 33 (2006), pp. 918-923

${ }^{19} \mathrm{~B}$. Akkayan, T. Gulmez. Resistance to fracture of endodontically treated teeth restored with different post systems. J Prosthet Dent, 87 (2002), pp. 431-437

${ }^{20} \mathrm{~N}$. Bittner, T. Hill, A. Randi. Evaluation of a one-piece milled zirconia post and core with different post-and-core systems: an in vitro study. J Prosthet Dent, 103 (2010), pp. 369-379

${ }^{21}$ Y. Goto, J.I. Nicholls, K.M. Phillips, T. Junge. Fatigue resistance of endodontically treated teeth restored with three dowel-and-core systems. J Prosthet Dent, 93 (2005), pp. 45-50

${ }^{22}$ S.H. Jung, K.S. Min, H.S. Chang, S.D. Park, S.N. Kwon, J.M. Bae. Microleakage and fracture patterns of teeth restored with different posts under dynamic loading. J Prosthet Dent, 98 (2007), pp. 270-276

${ }^{23}$ M.F. Ayad, S.A. Bahannan, S.F. Rosenstiel. Influence of irrigant, dowel type, and root-reinforcing material on fracture resistance of thin-walled endodontically treated teeth. J Prosthodont, 20 (2011), pp. 180-189

The Journal of Prosthetic Dentistry, Vol 114, No. 3 (September 2015): pg. 390-397. DOI. This article is (c) Elsevier and permission has been granted for this version to appear in e-Publications@Marquette. Elsevier does not grant permission for this article to be further copied/distributed or hosted elsewhere without the express permission from Elsevier. 
NOT THE PUBLISHED VERSION; this is the author's final, peer-reviewed manuscript. The published version may be

accessed by following the link in the citation at the bottom of the page.

${ }^{24}$ T. Junge, J.I. Nicholls, K.M. Phillips, W.J. Libman. Load fatigue of compromised teeth: a comparison of 3 luting cements. Int J Prosthodont, 11 (1998), pp. 558-564

${ }^{25} \mathrm{P}$. Bolhuis, A. de Gee, A. Feilzer. The influence of fatigue loading on the quality of the cement layer and retention strength of carbon fiber postresin composite core restorations. Oper Dent, 30 (2005), pp. 220-227

${ }^{26}$ D. Dietschi, O. Duc, I. Krejci, A. Sadan. Biomechanical considerations for the restoration of endodontically treated teeth: a systematic review of the literature, part II (Evaluation of fatigue behavior, interfaces, and in vivo studies). Quintessence Int, 39 (2008), pp. 117-129

${ }^{27}$ M. Naumann, G. Sterzenbach, M. Rosentritt, F. Beuer, R. Frankenberger. Is adhesive cementation of endodontic posts necessary? J Endod, 34 (2008), pp. 1006-1010

${ }^{28}$ P. Schmage, F.Y. Cakir, I. Nergiz, P. Pfeiffer. Effect of surface conditioning on the retentive bond strengths of fiberreinforced composite posts. J Prosthet Dent, 102 (2009), pp. 368-377

${ }^{29} \mathrm{M}$. Yenisey, S. Kulunk. Effects of chemical surface treatments of quartz and glass fiber posts on the retention of a composite resin. J Prosthet Dent, 99 (2008), pp. 38-45

${ }^{30}$ Z.S. Albashaireh, M. Ghazal, M. Kern. Effects of endodontic post surface treatment, dentin conditioning, and artificial aging on the retention of glass fiber-reinforced composite resin posts. J Prosthet Dent, 103 (2010), pp. 31-39

${ }^{31}$ Y. Choi, A. Pae, E.J. Park, R.F. Wright. The effect of surface treatment of fiber-reinforced posts on adhesion of a resin-based luting agent. J Prosthet Dent, 103 (2010), pp. 362-368

${ }^{32}$ B.J. Rasimick, J. Wan, B.L. Musikant, A.S. Deutsch. A review of failure modes in teeth restored with adhesively luted endodontic dowels. J Prosthodont, 19 (2010), pp. 639-646

${ }^{33}$ A.F. Santos, J.B. Meira, C.B. Tanaka, T.A. Xavier, R.Y. Ballester, R.G. Lima, et al. Can fiber posts increase root stresses and reduce fracture? J Dent Res, 89 (2010), pp. 587-591

${ }^{34} \mathrm{G}$. Akgungor, B. Akkayan. Influence of dentin bonding agents and polymerization modes on the bond strength between translucent fiber posts and three dentin regions within a post space. J Prosthet Dent, 95 (2006), pp. 368-378

${ }^{35} \mathrm{H}$. Yanagida, N. Tanoue, T. Ide, H. Matsumura. Evaluation of two dualfunctional primers and a tribochemical surface modification system applied to the bonding of an indirect composite resin to metals. Odontology, 97 (2009), pp. 103-108

${ }^{36}$ G. Plotino, N.M. Grande, R. Bedini, C.H. Pameijer, F. Somma. Flexural properties of endodontic posts and human root dentin. Dent Mater, 23 (2007), pp. 1129-1135

The Journal of Prosthetic Dentistry, Vol 114, No. 3 (September 2015): pg. 390-397. DOI. This article is @ Elsevier and permission has been granted for this version to appear in e-Publications@Marquette. Elsevier does not grant permission for this article to be further copied/distributed or hosted elsewhere without the express permission from Elsevier. 
NOT THE PUBLISHED VERSION; this is the author's final, peer-reviewed manuscript. The published version may be accessed by following the link in the citation at the bottom of the page.

${ }^{37}$ F.L. Amaral, V. Colucci, R.G. Palma-Dibb, S.A. Corona. Assessment of in vitro methods used to promote adhesive interface degradation: a critical review. J Esthet Restor Dent, 19 (2007), pp. 340-353

${ }^{38}$ H.W. Wiskott, J.I. Nicholls, U.C. Belser. Stress fatigue: basic principles and prosthodontic implications. Int J Prosthodont, 8 (1995), pp. 105-116

${ }^{39} \mathrm{~L}$. Laurell, D. Lundgren. A standardized programme for studying the occlusal force pattern during chewing and biting in prosthetically restored dentitions. J Oral Rehabil, 11 (1984), pp. 39-44

${ }^{40}$ S.C. Regalo, C.M. Santos, M. Vitti, C.A. Regalo, P.B. de Vasconcelos, W. Mestriner Jr., et al. Evaluation of molar and incisor bite force in indigenous compared with white population in Brazil. Arch Oral Biol, 53 (2008), pp. 282-286

${ }^{41}$ K.M. Hargreaves, S. Cohen. Cohen's pathways of the pulp. (10th ed.) Mosby, St Louis (2011), pp. 322-323

${ }^{42}$ R.O. Souza, G.H. Lombardo, S.M. Michida, G. Galhano, M.A. Bottino, L.F. Valandro. Influence of brush type as a carrier of adhesive solutions and paper points as an adhesive-excess remover on the resin bond to root dentin. J Adhes Dent, 9 (2007), pp. 521-526

${ }^{43} \mathrm{~S}$. Thitthaweerat, M. Nakajima, R.M. Foxton, J. Tagami. Effect of solvent evaporation strategies on regional bond strength of one-step self-etch adhesives to root canal dentine. Int Endod J, 46 (2013), pp. 10231031

${ }^{44}$ T.M. Aziz, M.N. Anwar, F.S. El-Askary. Push-out bond strength of fiber posts to root canal dentin using a one-step self-etching adhesive: the effect of solvent removal and light-curing methods. J Adhes Dent, 16 (2014), pp. 79-86

${ }^{45}$ K. Kitzmuller, A. Graf, D. Watts, A. Schedle. Setting kinetics and shrinkage of self-adhesive resin cements depend on cure-mode and temperature. Dent Mater, 27 (2011), pp. 544-551

46M. Oliveira, P.F. Cesar, M. Giannini, F.A. Rueggeberg, J. Rodrigues, C.A. Arrais. Effect of temperature on the degree of conversion and working time of dual-cured resin cements exposed to different curing conditions. Oper Dent, 37 (2012), pp. 370-379

Supported by the Baylor College of Dentistry Graduate Research Fund. Part of this study was presented as an oral presentation at the 41st Annual Meeting of the American Academy of Dental Research, March 2012, Tampa, Fla.

Corresponding author: Dr Georgios Maroulakos, 415 E Vine St, \#304, Milwaukee, WI 53212

The Journal of Prosthetic Dentistry, Vol 114, No. 3 (September 2015): pg. 390-397. DOI. This article is (C) Elsevier and permission has been granted for this version to appear in e-Publications@Marquette. Elsevier does not grant permission for this article to be further copied/distributed or hosted elsewhere without the express permission from Elsevier. 